ISSN 1981-416X

Licenciado sob uma Licença Creative Commons

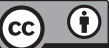

\title{
Saberes necessários à educação do futuro: Recursos Educacionais Abertos à luz do pensamento complexo
}

Knowledge needed for future education: Educational

Resources Open in the light of complex thinking

Saberes necesarios para la educación del futuro: Recursos Educativos Abiertos a la luz del pensamiento complejo

\section{Claudia Cristine Souza Appel Gonçalves, Ricardo Antunes de Sá*}

Universidade Federal do Paraná (UFPR), Curitiba, PR, Brasil

\section{Resumo}

O presente estudo apresenta o desenvolvimento de um curso de formação continuada on-line para professores e pedagogos da Secretaria de Estado da Educação do Paraná (SEED-PR), do município de Campina Grande do Sul, com a intenção de produzir Recursos Educacionais Abertos à luz do pensamento complexo. A abordagem metodológica qualitativa utilizada foi a pesquisa colaborativa (FERREIRA; IBIAPINA, 2011). Tem-se como embasamento teórico: Morin (2000, 2011), Pereira (2015), Petraglia (2011), Sá et al. (2013), Santos (2013). Foram analisados oito Recursos Educacionais Abertos produzidos pelos participantes do estudo durante o curso. Destaca-se que a produção de Recursos Educacionais

*CCSAG: Mestre em Educação, e-mail: clauealex1@gmail.com

RAS: Doutor em Educação, e-mail: antunesdesa@gmail.com 
Abertos pelos professores e pedagogos estimulou a pesquisa e a inovação pedagógica. Além disso, contribuiu para reflexões teóricas e práticas sobre a educação do presente e do futuro. Os resultados destacaram que os professores e pedagogos participaram colaborativamente do curso, das reflexões teóricas e das práticas propostas. Conclui-se que o curso de formação continuada on-line desenvolvido aponta um caminho possível de metodologia inovadora para a construção de novos saberes e, consequentemente, possibilidade de mudança da prática pedagógica de professores e pedagogos.

Palavras-chave: Formação continuada on-line. Pensamento complexo. Recursos Educacionais Abertos.

\section{Abstract}

The present study presents the development of a continuous online training course for teachers and pedagogues of the State Secretariat of Education of the Paraná (SEED-PR), of the municipality of Campina Grande do Sul with the intention of producing Open Educational Resources in the light of complex thinking. The qualitative methodological approach used was collaborative research (FERREIRA; IBIAPINA, 2011). The theoretical basis is: Morin (2000, 2011), Pereira (2015), Petraglia (2011), Sá et al. (2013), Santos (2013). Eight Open Educational Resources produced by study participants during the course were analyzed. It is emphasized that the production of Open Educational Resources by teachers and pedagogues stimulated research and pedagogical innovation. Contributed to theoretical and practical reflections on the education of the present and the future. The results pointed out that teachers and pedagogues participated collaboratively in the course, theoretical reflections and proposed practices. It is concluded that the course of online training developed, points out the possible path of an innovative methodology for the construction of new knowledge and, consequently, the possibility of change in the pedagogical practice of teachers and pedagogues.

Keywords: Online continuing education. Complex thinking. Open Educational Resources. 


\section{Resumen}

El presente estudio presenta el desarrollo de curso de formación continuada on line para profesores y pedagogos de la Secretaría de Estado de Educación del Estado Paraná (SEED-PR), del municipio de Campina Grande do Sul con la intención de producir Recursos Educacionales Abiertos a la luz del pensamiento complejo. El enfoque metodológico cualitativo utilizado fue la investigación colaborativa (FERREIRA; IBIAPINA, 2011). Se tiene como base teórica Morin (2000, 2011), Pereira (2015), Petraglia (2011), Sá et al. (2013), Santos (2013). Se analizaron ocho Recursos Educativos Abiertos producidos por los participantes del estudio durante el curso. Se destaca que la producción de Recursos Educacionales Abiertos por los profesores y pedagogos estimuló la investigación y la innovación pedagógica. Contribuyó a reflexiones teóricas y prácticas sobre la educación del presente y del futuro. Los resultados destacaron que los profesores y pedagogos participaron colaborativamente del curso, de las reflexiones teóricas y de las prácticas propuestas. Se concluye que el curso de formación continuada en línea desarrollado, apunta camino posible de metodología innovadora para la construcción de nuevos saberes y, consecuentemente, posibilidad de cambio de la práctica pedagógica de profesores y pedagogos.

Palabras claves: Formación continuada en línea. Pensamiento complejo. Saberes necessários. Recursos Educativos Abiertos.

\section{Introdução}

Com o avanço e uso das tecnologias da informação e da comunicação, as pesquisas sobre a temática formação continuada dos professores para a utilização da Tecnologia da Informação e Comunicação (TIC), diante da revolução digital pela qual a sociedade contemporânea passa, têm aumentado significativamente. Este artigo tem por objetivo apresentar suscintamente os resultados da pesquisa colaborativa desenvolvida por meio do curso: Saberes necessários à educação do futuro: recursos 
educacionais abertos à luz do pensamento complexo, aplicado no primeiro semestre de 2018 para professores e pedagogos da Rede Estadual de Educação do Paraná, do município de Campina Grande do Sul ${ }^{1}$.

Os Recursos Educacionais Abertos (REA) podem proporcionar a disseminação de materiais pedagógicos de forma colaborativa. Professores e pedagogos podem utilizar, reutilizar, distribuir, remixar, adaptar e criar REA em formato digital de qualquer lugar que tenha acesso à internet. REA são "[...] recursos de ensino, aprendizagem e pesquisa que estejam em domínio público, ou que tenham sido disponibilizados com uma licença de propriedade intelectual que permita seu uso e adaptação por terceiros" (SANTOS, 2013, p. 21). O embasamento teórico utilizado para a produção dos REA ao longo do curso foram os pressupostos teóricos do pensamento complexo sistematizado pelo filósofo, epistemólogo e sociólogo Edgar Morin. O autor (2011b, p. 36) conceitua complexidade a partir do termo complexus:

Complexus significa o que foi tecido; de fato, há complexidade quando elementos diferentes são inseparáveis constitutivos do todo (como o econômico, o político, o sociológico, o psicológico, o afetivo, o mitológico), e há um tecido interdependente, interativo e interretroativo entre o objeto de conhecimento e seu contexto, as partes e o todo, o todo e as partes, as partes entre si (MORIN, 2011, p. 36).

Complexidade é o todo e as partes numa dinâmica multidimensional e interdependente. A "complexidade é a qualidade do que é complexo" (PETRAGLIA, 2011, p. 59). De acordo com Petraglia (2011), o todo não é a soma das partes, porque as partes são interdependentes, com especificidades, que se modificam em contato com as outras partes e, consequentemente, modificam o todo. Morin (2011b, p. 13) complementa que complexidade, num primeiro olhar, "[...] coloca o paradoxo do uno e do múltiplo. Num segundo momento, a complexidade é efetivamente o tecido de acontecimentos, ações, interações, retroações, determinações,

${ }^{1}$ Este estudo faz parte de pesquisa de Doutorado em andamento. 
acasos, que constituem nosso mundo fenomênico". Podemos dizer, então, que complexidade é o todo e as partes numa dinâmica multidimensional e interdependente.

Ao longo do curso on-line foi utilizado o livro: Os sete saberes necessários à educação do futuro que foi escrito por Morin, em 2000, a pedido da Organização das Nações Unidas para a Educação, a Ciência e a Cultura (UNESCO). O livro sintetiza, de certa forma, os grandes princípios epistemológicos do pensamento complexo. A intenção foi propiciar aos professores e pedagogos um conhecimento preliminar sobre os pressupostos teóricos do pensamento complexo, os quais serviriam de fundamentação para se poder elaborar e/ou produzir REAS que se constituem em um material pedagógico de uso colaborativo, sob uma nova concepção teórico-metodológica: pensamento complexo. Descreve-se a seguir o estudo realizado com o curso de formação continuada on-line.

\section{Experiência de formação on-line para professores e pedagogos: Recursos Educacionais Abertos à luz do pensamento complexo}

Como metodologia de pesquisa qualitativa, utilizamos a pesquisa colaborativa (FERREIRA; IBIAPINA, 2011). A pesquisa qualitativa permite uma construção flexível na construção do conhecimento. De acordo com Ferreira e Ibiapina (2011, p. 122):

A pesquisa colaborativa propõe abordagem em que os objetivos da pesquisa e da formação se encontram imbricados, exigindo a inter-relação entre os atores do processo, distinguindo-se de outras modalidades pelo caráter de participação, colaboração e reflexão crítica que lhe é inerente. [...] pesquisar, na proposta colaborativa, implica refletir sobre o agir e sobre as teorias que lhe servem de esteio, como também criar formas de interpretá-los e transformá-los (FERREIRA; IBIAPINA, 2011, p. 122).

Pesquisador e participantes constroem a pesquisa de forma colaborativa. O pesquisador tem a função de mediar o processo de pesquisa 
baseando-se nas contribuições dos participantes. A presente pesquisa parte do pressuposto de que o objeto de estudo está inserido na teia de interações do meio social, histórico, pedagógico e cultural. "A complexidade integra os modos simplificadores do pensar e consequentemente nega os resultados mutiladores, unidimensionais e reducionistas" (PETRAGLIA, 2011, p. 58). Nessa perspectiva de investigação, a formação e a pesquisa estão intercaladas. Os participantes atuam ativamente no processo de produção de conhecimentos, ao mesmo tempo em que refletem sobre sua prática a partir da teoria trabalhada.

Os colaboradores do estudo são professores e pedagogos da Secretaria Estadual de Educação do Paraná (SEED-PR), do município de Campina Grande do Sul. Os participantes e o campo de pesquisa foram escolhidos tendo em vista a continuidade de pesquisa realizada durante Mestrado em $2011^{2}$. Os professores possuem os conhecimentos específicos das disciplinas que lecionam e os pedagogos possuem os conhecimentos pedagógicos. Aqueles que têm a função de mediar o processo de ensino e aprendizagem na escola, para que os conhecimentos específicos de cada disciplina possam ser ensinados e compreendidos de forma organizada, coerente e significativa para os estudantes. Para este estudo, um recorte de uma pesquisa de doutorado, foram escolhidos oito participantes que concluíram todas as etapas do curso de formação continuada on-line.

O processo de investigação colaborativa ocorreu por meio do curso Saberes necessários à educação do futuro: recursos educacionais abertos à luz do pensamento complexo, divulgado durante o mês de fevereiro de 2018 em todas as escolas estaduais do município mencionado. No formulário de inscrição, os objetivos da pesquisa estavam descritos garantindo a confiabilidade e ética na pesquisa ${ }^{3}$. Inscreveram-se para o curso 27 pro-

2 O objetivo da pesquisa de Mestrado foi a análise das formações continuadas para utilização do laboratório de informática, ocorridas entre 1998 e 2010, ofertadas pela SEED-PR aos professores. Foi realizada no município de Campina Grande do Sul.

${ }^{3}$ Este estudo foi submetido ao comitê de ética da UFPR (Parecer de autorização número 2.300.654) e foi autorizado pela SEED-PR (Parecer de autorização número 14.763.379-3). 
fessores e pedagogos. A formação inicial dos participantes inscritos é bem diversificada, sendo que cinco tinham formação em duas disciplinas e um, em três disciplinas, conforme sistematizado no Quadro 1.

Quadro 1 - Formação inicial dos participantes do curso de formação on-line.

\begin{tabular}{|l|c|l|c|}
\hline \multicolumn{1}{|c|}{ DISCIPLINA } & QUANTIDADE & \multicolumn{1}{c|}{ DISCIPLINA } & QUANTIDADE \\
\hline ARTE & 3 & MATEMÁTICA & 3 \\
\hline BIOLOGIA & 1 & QUÍMICA & 2 \\
\hline CIÊNCIAS & 2 & FÍSICA & 1 \\
\hline HISTÓRIA & 1 & FILOSOFIA & 1 \\
\hline GEOGRAFIA & 2 & PEDAGOGIA & 9 \\
\hline LÍNGUA PORTUGUESA & 4 & TEOLOGIA & 1 \\
\hline LÍNGUA ESTRANGEIRA & 3 & & \\
\hline
\end{tabular}

Fonte: Gonçalves e Sá (2018).

Iniciaram o curso 25 participantes, destes, oito concluíram todas as atividades do curso, com a produção dos Recursos Educacionais Abertos. As oito produções estão destacadas no decorrer deste artigo.

$O$ curso de formação continuada on-line foi hospedado no Moodle $\mathrm{UFPR}^{4}$ e teve a duração de dois meses e meio. Foi realizado no primeiro semestre de 2018, contendo cinco módulos, sob a modalidade a distância, totalizando 70 horas. O curso teve como embasamento teórico o livro: Os sete saberes necessários à educação do futuro de Morin ${ }^{5}$, de acordo com a Figura 1. Os pressupostos teóricos do pensamento complexo sintetizados nesta obra serviram de fundamentação para que os cursistas pudessem elaborar/produzir os REAS.

${ }^{4}$ Moodle oficial da UFPR. Disponível em: <https://ava.ufpr.br/?redirect=0>. Acesso em: 03 jul. 2018.

${ }^{5}$ MORIN, E. Os Sete Saberes necessário à Educação do Futuro. São Paulo: Cortez; Brasília: UNESCO, 2000. Disponível em: <https://bioetica.catedraunesco.unb.br/wp-content/uploads/2016/04/ Edgar-Morin.-Sete-Saberes.pdf >. Acesso em: 03 abr. 2018. 
Figura 1 - Página inicial do Curso: Saberes necessários à educação do futuro: Recursos Educacionais Abertos à luz do pensamento complexo.

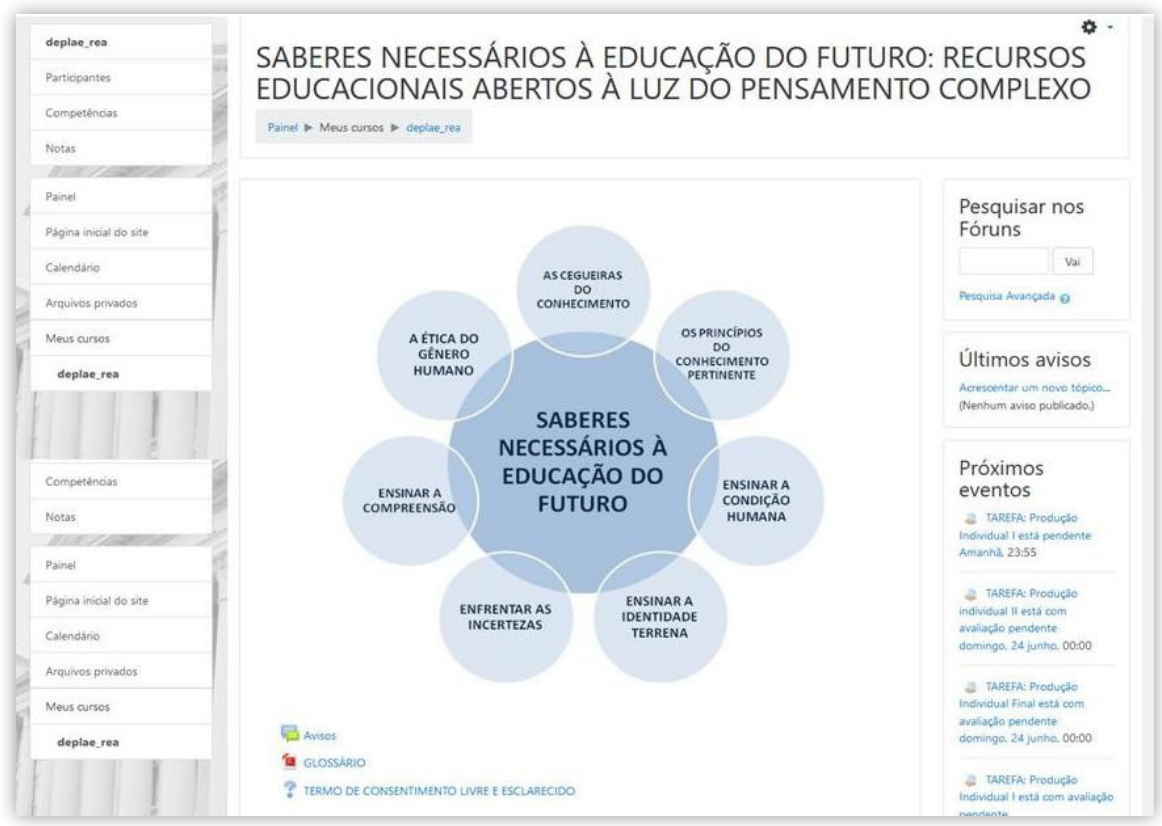

Fonte: Gonçalves e Sá (2018).

$\mathrm{Na}$ obra Os sete saberes necessários à educação do futuro, Morin (2000) apresenta os saberes que julga serem fundamentais para a reforma da educação para um mundo cada vez mais planetarizado e complexo. No primeiro módulo do curso (Apresentação) foram tratadas as informações gerais do curso: a) o roteiro de estudo; b) o material "Conhecendo o ambiente virtual de aprendizagem"; c) o questionário inicial para saber do conhecimento prévio sobre as temáticas pelos participantes; d) o Fórum de Apresentação para que os participantes pudessem se conhecer, permitindo um processo de interação; e) a Estrutura do curso; f) um material introdutório sobre o pensamento complexo de Edgar Morin; g) e uma introdução sobre os Recursos Educacionais Abertos. 
No segundo módulo, foram apresentadas as indicações de leituras dos capítulos I e II do livro de referência e os artigos: A escola e os sete saberes: reflexões para avanços inovadores no processo educativo ${ }^{6}$, Resenha: Os sete saberes necessários à educação do futuro ${ }^{7}$, Resenha bibliográfica ${ }^{8}$, que serviram de fundamentação teórica para o conhecimento preliminar do pensamento complexo. Além dessas leituras de base, foram disponibilizados: o Vídeo Sete Saberes Necessários para Educação do Futuro Edgar Morin 19, os materiais de estudo elaborados a partir dos dois primeiros capítulos do livro de Morin e o Vídeo Direitos autorais e licenças - Luciane Hilu ${ }^{10}$.

No terceiro módulo, além dos capítulos três e quatro do livro de referência e os materiais de estudos elaborados a partir destes capítulos, foram disponibilizados o material: Como buscar imagens com Licença Aberta, o qual serviu como base para a Produção Individual II.

Para o módulo IV, foram disponibilizados materiais de apoio referentes aos capítulos cinco, seis e sete do livro de referência e estes capítulos na íntegra. Para a Produção Individual III, foi elaborado e disponibilizado o material Como buscar vídeos com Licença Aberta.

${ }^{6}$ SÁ, R. A.; CARNEIRO, S. M. M.; LUZ, A. A. A escola e os sete saberes: reflexões para avanços inovadores no processo educativo. Revista da FAEEBA - Educação e Contemporaneidade, Salvador, v. 22, n. 39, p. 159-169, jan./jun. 2013. Disponível em: <www.revistas.uneb.br/index.php/faeeba/ article/download/336/286>. Acesso em: 03 jul. 2018.

${ }^{7}$ BIZARRIA, F. P. A. Resenha: Os sete saberes necessários à educação do futuro. Debates em Educação, Maceió, v. 7, n. 13, jan./jun. 2015. Disponível em: <http://www.seer.ufal.br/index.php/ debateseducacao/article/view/891/0>. Acesso em: 03 abr. 2018.

${ }^{8}$ OLIVEIRA, C. P. S. Resenha bibliográfica. Revista de Ensino de Geografia, Uberlândia, v. 7, n. 12, p. 148-150, jan./jun. 2016. Disponível em: <http://www.revistaensinogeografia.ig.ufu.br/N12/ Resenha-1-Revista-Ensino-Geografia-v7-n12-Oliveira.pdf>. Acesso em: 03 jul. 2018.

${ }^{9}$ YOUTUBE. Vídeo Sete Saberes Necessários para Educação do Futuro Edgar Morin 1. Disponível em: <https://www.youtube.com/watch?v=xY2WRhN7jgw>. Acesso em: 03 abr. 2018.

${ }^{10}$ YOUTUBE. Vídeo Direitos autorais e licenças - Luciane Hilu. Disponível em: <https://www.youtube. com/watch?v=fkZ1U_ExB2M>. Acesso em: 03 abr. 2018. 
No decorrer do segundo, terceiro e quarto módulos os participantes discutiram questões sobre o pensamento complexo contidas no livro: Os sete saberes necessários à educação do futuro nos Fóruns de discussão e nos artigos sugeridos. Cada Fórum proporcionou a reflexão sobre uma temática, sendo elas: As cegueiras do conhecimento: o erro e a ilusão, Os princípios do conhecimento pertinente, Ensinar a condição humana, Ensinar a identidade terrena, Enfrentar as incertezas, Ensinar a compreensão e A ética do gênero humano, conforme a Figura 2, o que possibilitou reflexões teóricas colaborativas sobre o pensamento complexo, dando fundamentação para as Produções Individuais. Cada participante realizou uma postagem própria sobre a questão levantada no Fórum e uma postagem realizando reflexões a partir da postagem de outro participante. As postagens necessitavam estar fundamentadas nos materiais de estudo disponibilizados no Ambiente Virtual de Aprendizagem ou em outros materiais sobre a temática.

Figura 2 - Fórum de discussão I do Módulo II.

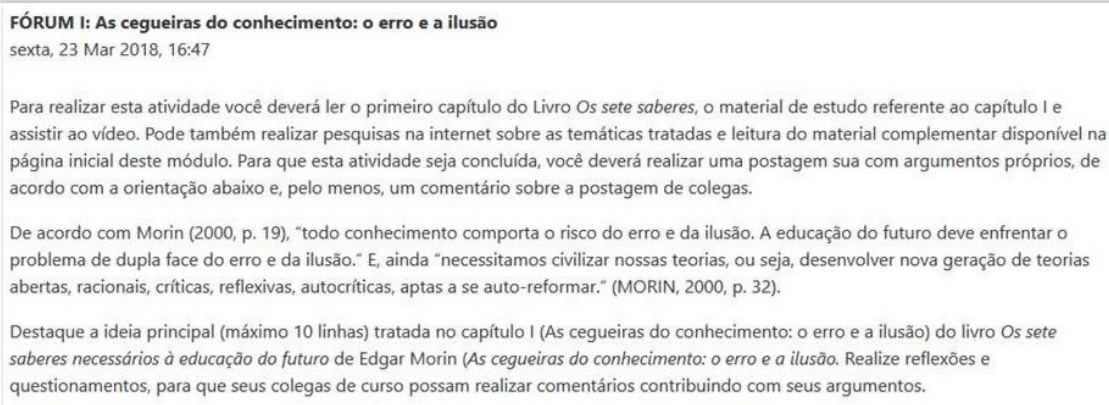

Fonte: Gonçalves e Sá (2018).

Ao mesmo tempo, as "Tarefas: Produção Individual I, II, III e Final" proporcionaram o estudo para a produção de Recurso Educacional Aberto, em etapas nos módulos do curso. A atividade individual foi 
retomada em cada módulo e, até o final do curso, o Recurso Educacional Aberto (REA) foi sendo elaborado, reelaborado e finalizado.

Ao longo do curso, foi trabalhado o conceito de licença aberta e como procurar, utilizar, produzir e publicar materiais pedagógicos em licença aberta. A licença é aberta quando os recursos educacionais são disponibilizados ou são protegidos por restrições relativas aos direitos autorais que permitem o seu uso, porém não autorizam fundamentalmente a sua alteração e/ou são licenciados com licenças Creative Commons ${ }^{11}$.

De acordo com Pereira, Creative Commons é:

[...] uma organização sem fins lucrativos, criada em 19 de dezembro de 2002, por Lawrence Lessig, juntamente com outros membros da Escola de Direito de Harvard. No Brasil, a Creative Commons é administrada pelo Centro de Tecnologia e Sociedade, da Faculdade de Direito da Fundação Getúlio Vargas, no Rio de Janeiro. (PEREIRA, 2015, p. 64).

Ao final do curso o material de estudo sobre como publicar com a licença Creative Commons os seus materiais produzidos foi disponibilizado. No Quadro 2 estão descritas as licenças, as quais vão desde a mais livre e aberta, até a que possui mais restrições.

Quadro 2 - Licenças Creative Commons

(continua)

\begin{tabular}{|c|l|}
\hline LICENÇA & \multicolumn{1}{c|}{ PERMISSÃo } \\
\hline CC & $\begin{array}{l}\text { Permite que outros distribuam, remixem, adaptem e criem a partir do } \\
\text { trabalho, mesmo para fins comerciais, desde que atribuam ao autor o } \\
\text { devido crédito pela criação original. }\end{array}$ \\
\hline CC & $\begin{array}{l}\text { Permite a redistribuição, comercial e não comercial, desde que o } \\
\text { trabalho seja distribuído inalterado e no seu todo, com crédito atribuído } \\
\text { ao autor. }\end{array}$ \\
\hline C. & $\begin{array}{l}\text { Permite que outros remixem, adaptem e criem a partir do trabalho para } \\
\text { fins não comerciais, desde que atribuam ao autor o devido crédito e que } \\
\text { licenciem as novas criações sob termos idênticos. }\end{array}$ \\
\hline
\end{tabular}

${ }^{11}$ CREATIVE COMMONS BRASIL. Disponível em: <http://www.creativecommons.org.br/>. Acesso em: 28 maio 2018. 
(conclusão)

\begin{tabular}{|c|l|}
\hline \multicolumn{1}{|c|}{ LICENÇA } & \multicolumn{1}{c|}{ PERMISSÃo } \\
\hline CC & $\begin{array}{l}\text { Permite que outros remixem, adaptem e criem a partir do trabalho, } \\
\text { mesmo para fins comerciais, desde que atribuam ao autor o devido } \\
\text { crédito e que licenciem as novas criações sob termos idênticos. }\end{array}$ \\
\hline CC & $\begin{array}{l}\text { Permite que outros remixem, adaptem e criem a partir do trabalho para } \\
\text { fins não comerciais, e embora os novos trabalhos tenham de atribuir ao } \\
\text { autor o devido crédito e não possam ser usados para fins comerciais, os } \\
\text { usuários não têm de licenciar esses trabalhos derivados sob os } \\
\text { mesmos termos. }\end{array}$ \\
\hline CC & $\begin{array}{l}\text { Esta é a mais restritiva das seis licenças principais, só permitindo que } \\
\text { outros façam download dos trabalhos e os compartilhem desde que } \\
\text { atribuam crédito ao autor, mas sem que possam alterá-los de nenhuma } \\
\text { forma ou utilizá-los para fins comerciais. }\end{array}$ \\
\hline
\end{tabular}

Fonte: Creative Commons. Disponível em: <http://creativecommons.org/license>. Acesso em: 28 mai. 2018.

Para o quinto Módulo, os participantes tiveram duas semanas para a construção da "Tarefa Individual Final" e mais uma semana para as alterações após o Feedback da docente, que consistiu na finalização e sistematização do que foi estudado durante o curso. Apresentam-se os resultados a partir da Produção Final dos participantes do curso — Produção de REA à luz do pensamento complexo.

\section{Resultados}

Os participantes do curso ficaram imersos nos estudos e reflexões sobre o pensamento complexo, a partir da obra já citada e dos artigos de referência disponibilizados, durante todos os módulos. O processo de estudos ocorreu de forma colaborativa, sob a mediação da pesquisadora/ docente. Foram gradualmente construindo uma compreensão teórica sobre o pensamento complexo de Edgar Morin, que serviu de fundamentação para a produção de um relato de experiência (REA). A compreensão teórica foi construída pelas reflexões e discussões realizadas nos Fóruns, na sistematização nas atividades individuais que estão descritas no decorrer deste artigo. Ao mesmo tempo, os cursistas tiveram conhecimento sobre as características do processo de elaboração dos Recursos Educacionais 
Abertos, desde a conceituação, passando pela busca e utilização de materiais em Licença Aberta, até a produção e publicação de REA.

Em cada módulo, os participantes tiveram acesso a atividades de discussão teórica colaborativa nos Fóruns e de produção individual prática, conforme Quadro 3, nas Tarefas.

Quadro 3 - Produções Individuais do Curso - Saberes necessários à educação do futuro: Recursos Educacionais Abertos à luz do pensamento complexo.

\begin{tabular}{|c|l|}
\hline Módulos & \multicolumn{1}{c|}{ Descrição } \\
\hline I & Introdução ao Pensamento Complexo e aos REA. \\
\hline II & $\begin{array}{l}\text { Produção de uma lauda destacando um conhecimento, de sua disciplina de } \\
\text { formação e/ou atuação, que foi reelaborado ou substituído por cientistas a } \\
\text { partir de pesquisas realizadas (relacionando com os capítulos I As cegueiras do } \\
\text { conhecimento: o erro e a ilusão e II Os princípios do conhecimento pertinente do } \\
\text { livro de referência). }\end{array}$ \\
\hline III & $\begin{array}{l}\text { Busca de imagens (REA) que estejam relacionadas ao tema/conteúdo/ } \\
\text { conhecimento descrito no texto que foi iniciado no módulo II, escrevendo mais } \\
\text { uma lauda (relacionando com os capítulos III Ensinar a condição humana e IV } \\
\text { Ensinar a identidade terrena do livro de referência). }\end{array}$ \\
\hline IV & $\begin{array}{l}\text { Escolha de um vídeo (Licença Aberta ou Domínio Público) que represente } \\
\text { alguma temática que foi tratada nos últimos três capítulos do livro de referência: } \\
\text { Enfrentar as incertezas, Ensinar a compreensão e } A \text { ética do gênero humano e que } \\
\text { tenha relação com o conhecimento/tema que escolheu nos módulos anteriores, } \\
\text { dando continuidade a produção. }\end{array}$ \\
\hline V & $\begin{array}{l}\text { Finalização do texto acrescentando uma Proposta Prática (Aula do conteúdo/ } \\
\text { temática do texto). Construir uma experiência vivenciada ou prática a } \\
\text { ser desenvolvida. }\end{array}$ \\
\hline
\end{tabular}

Fonte: Gonçalves e Sá (2018).

A produção individual ocorreu de forma gradativa, sempre com feedback após cada atividade concluída, para que o participante pudesse rever o que fosse necessário. A produção individual final seguiu uma estrutura de relato de experiência, contendo: título, autor, e-mail, introdução 
(embasamento teórico sobre o pensamento complexo), proposta prática, conforme Figura 3, considerações finais e referências.

Figura 3 - Produção Individual Final (REA)

TAREFA: Produção Individual Final

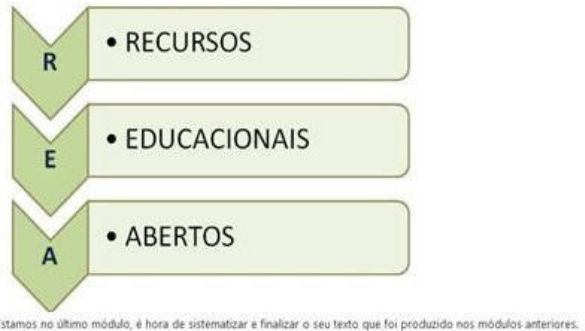

Voct tera 2 somunus para realizar a primeira versalo da tarefa final. Oepois mais uma semana para as aterasbes finais e postagem final

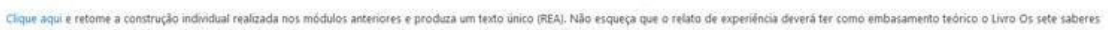

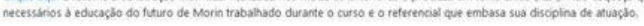

Retome os materiain

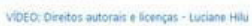

COMO EUSCAR MMAGENS COM UCENCG AEERTA

COMO BUSCAR VDEOOS COM LKENĢA AEERTA

veja os passos do materisl abacos, para pablicar materias com licenca Creative Commons:

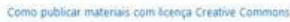

Copie o texto que esta no modilo IV na TAREFA Mroduçio indisitual it

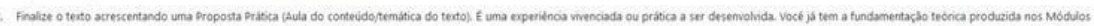

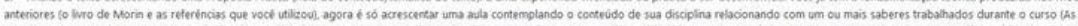

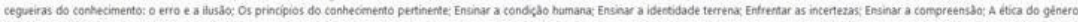
humano).

3. Clique aqui para ver o modelo de satrutura do terto.

4. PROPOSTA PRATCA: Relato de aula devera conter:

corteudo/tema:

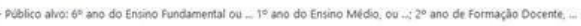

objetives

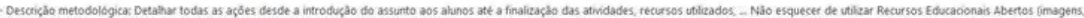
ideos esquemas at tendo como embasamento teócrico os sate Saberes propostos por Morin

- Avahacho:

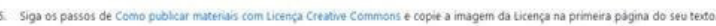

6. Poste o texto para que possa ser analiado pela professora tutora ate 03/0brie.

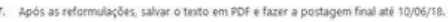

Fonte: Página da Tarefa Individual do Curso de Formação continuada on-line (GONÇALVES; SÁ, 2018).

Apresenta-se a seguir, no Quadro 4, os REA produzidos pelos participantes do curso, destacando a temática trabalhada em cada um 
deles. Utilizamos P1 (participante 1), P2, P3, etc... para manter o anonimato dos dados pessoais dos participantes.

Quadro 4 - Produção Individual Final (REA) produzidos pelos participantes do curso

\begin{tabular}{|c|c|}
\hline \multicolumn{2}{|r|}{ P1 } \\
\hline DISCIPLINA & FÍSICA \\
\hline Título do Relato de Experiência & Calor como substância \\
\hline Conteúdo/Temática da Proposta Prática & Calor e irradiação térmica \\
\hline Público Alvo & 2ㅇ ano do Ensino Médio \\
\hline \multicolumn{2}{|r|}{ P2 } \\
\hline Disciplina & Língua Portuguesa \\
\hline Título do Relato de Experiência & História da língua portuguesa \\
\hline Conteúdo/Temática da Proposta Prática & $\begin{array}{l}\text { Estudo das Zonas Dialetais e sotaques do } \\
\text { Português brasileiro. }\end{array}$ \\
\hline Público Alvo & 1ํano do Ensino Médio \\
\hline \multicolumn{2}{|r|}{ P3 } \\
\hline Disciplina & Língua Inglesa \\
\hline Título do Relato de Experiência & Motivação e recursos educacionais abertos \\
\hline Conteúdo/Temática da Proposta Prática & Uso de músicas em língua Inglesa \\
\hline Público Alvo & Ensino fundamental 60 ao 9 ㅇ ano \\
\hline \multicolumn{2}{|r|}{ P4 } \\
\hline Disciplina & Pedagogia \\
\hline Título do Relato de Experiência & A construção do conhecimento e a sua totalidade \\
\hline Conteúdo/Temática da Proposta Prática & Família \\
\hline Público Alvo & Infantil 4- Pré-escola - Educação Infantil \\
\hline \multicolumn{2}{|r|}{ P5 } \\
\hline Disciplina & Biologia \\
\hline Título do Relato de Experiência & $\begin{array}{l}\text { Mudança na nomenclatura e anatomia do corpo } \\
\text { humano }\end{array}$ \\
\hline Conteúdo/Temática da Proposta Prática & Citologia - estudo das células \\
\hline Público Alvo & 10 ano do Ensino Médio \\
\hline
\end{tabular}


(conclusão)

\begin{tabular}{|l|l|}
\hline \multicolumn{2}{|c|}{ P6 } \\
\hline Disciplina & Pedagogia \\
\hline Título do Relato de Experiência & Educação e transformação \\
\hline Conteúdo/Temática da Proposta Prática & Alimentação saudável e transtornos alimentares \\
\hline Público Alvo & 6o ano de Ensino Fundamental II \\
\hline & \multicolumn{1}{|c|}{ P7 } \\
\hline Disciplina & Geografia \\
\hline Título do Relato de Experiência & $\begin{array}{l}\text { O que é mais importante os resultados ou } \\
\text { assimilações de conteúdos }\end{array}$ \\
\hline Conteúdo/Temática da Proposta Prática & $\begin{array}{l}\text { A Geografia Inclusiva no uso das novas tecnologias de } \\
\text { ensino, desafios e inovações para o Ensino Médio. }\end{array}$ \\
\hline Público Alvo & 1o ano do Ensino Médio \\
\hline & \multicolumn{1}{|c|}{ P8 } \\
\hline Disciplina & Pedagogia \\
\hline Título do Relato de Experiência & Educação do futuro: ensinar a pensar \\
\hline Conteúdo/Temática da Proposta Prática & Família \\
\hline Público Alvo & Educação Infantil - Infantil IV \\
\hline
\end{tabular}

Fonte: Gonçalves e Sá (2018).

Cada Recurso Educacional Aberto, produzido pelos participantes do curso, agregou os conhecimentos específicos da disciplina de formação, a inserção de imagens, de vídeos e de textos com licença aberta ou em domínio público, tendo como aporte teórico os pressupostos do pensamento complexo. Para exemplificarmos essa articulação, trazemos recortes de uma produção individual no Quadro 5.

Quadro 5 - Produção Individual Final (REA): Calor como substância (continua)

\begin{tabular}{|l|l|}
\hline \multicolumn{2}{|c|}{ P1 } \\
\hline Disciplina & Física \\
\hline $\begin{array}{l}\text { Título do Relato de } \\
\text { Experiência }\end{array}$ & Calor como substância \\
\hline $\begin{array}{l}\text { Conteúdo/Temática da } \\
\text { Proposta Prática }\end{array}$ & Calor e irradiação térmica \\
\hline
\end{tabular}


(conclusão)

\begin{tabular}{|c|c|}
\hline \multicolumn{2}{|r|}{ P1 } \\
\hline Público Alvo & 2ㅇ ano do Ensino Médio \\
\hline $\begin{array}{l}\text { Conceito atual } \\
\text { relacionado com }\end{array}$ & $\begin{array}{l}\text { O calor é uma forma de energia em trânsito entre corpos ou sistemas, } \\
\text { em virtude da diferença de temperaturas entre eles. Este é o conceito } \\
\text { atual para calor, no entanto houve outras teorias para sua definição, } \\
\text { como a teoria do calórico. [...] De acordo com Morin (2000), o } \\
\text { desenvolvimento do conhecimento científico é poderoso meio de } \\
\text { detecção dos erros e de luta contra as ilusões e que nenhuma teoria } \\
\text { científica está imune para sempre contra o erro. Dessa forma, pelos } \\
\text { questionamentos de que a teoria do calórico não era suficiente para } \\
\text { explicar fenômenos como o aquecimento provocado pelo atrito entre } \\
\text { dois objetos, por exemplo, que foi reelaborado o conceito de calor } \\
\text { como uma forma de energia. }\end{array}$ \\
\hline $\begin{array}{l}\text { Figuras com licença } \\
\text { aberta inseridas na } \\
\text { produção }\end{array}$ & $\begin{array}{l}\text { FIGURA } 1 \text { - Ilhas de calor - Centro Antigo de São Paulo. Fonte: Centro } \\
\text { Antigo de São Paulo - by Lucas.JPG|thumb|180px|Legenda. } \\
\text { Figura } 2 \text { - Sol - irradiação de calor. Fonte: } \\
\text { PIXABAY. Disponível em: https://pixabay.com/pt/ } \\
\text { calor-ver\%C3\%A3o-sun-recorde-de-calor-834468/. } \\
\text { Figura } 3 \text { - Calor imagem infravermelho - irradiação térmica. } \\
\text { Fonte: PIXABAY. Disponível em: https://pixabay.com/pt/ } \\
\text { calor-imagem-infravermelho-87276/ }\end{array}$ \\
\hline $\begin{array}{l}\text { Vídeos com licença } \\
\text { aberta inseridos na } \\
\text { produção }\end{array}$ & $\begin{array}{l}\text { Vídeo: O que causa o aquecimento global retrata as mudanças } \\
\text { climáticas como consequências do aquecimento do planeta, o que } \\
\text { pode colocar em risco a vida aqui na Terra. Vídeo disponível em: } \\
\text { https://www.youtube.com/watch?v=Oe0npq64-LI. Acesso em: } \\
16 \text { mai. } 2018 . \\
\text { Vídeo: Como as mudanças climáticas mudarão nossas vidas em 2050? } \\
\text { Vídeo disponível em: https://www.youtube.com/watch?-v=0QoZ8hh8- } \\
\text { Qg. Acesso em: } 22 \text { mai. 2018. }\end{array}$ \\
\hline $\begin{array}{l}\text { Recortes das } \\
\text { considerações finais }\end{array}$ & $\begin{array}{l}\text { Sendo uma produção humana, os conhecimentos não representam } \\
\text { verdades absolutas, visto que somos passíveis de erros e acertos. } \\
\text { Talvez para determinada época, período ou contexto, podem até } \\
\text { se traduzir como imutáveis e dar conta das necessidades daquela } \\
\text { sociedade. No entanto, principalmente pelos avanços tecnológicos e } \\
\text { científicos, podem sofrer reformulações, ser mudado ou até mesmo } \\
\text { substituído por uma teoria mais completa de acordo com os moldes } \\
\text { ou contextos da atualidade. Assim, não devemos cair no erro do } \\
\text { conhecimento pronto e acabado, que nos levam a ilusões de } \\
\text { verdades absolutas. }\end{array}$ \\
\hline
\end{tabular}

Fonte: Gonçalves e Sá (2018).

Nessa produção, o Participante 1 trouxe como tema central a construção do conteúdo Calor e irradiação térmica com o passar do tempo. Relacionou com o desenvolvimento do conhecimento científico e as 
cegueiras do conhecimento - erro e ilusão (MORIN, 2011), além de utilizar imagens e vídeos com licença aberta conforme a temática tratada.

Analisando os relatos de experiências (REA) produzidos pelos professores e pedagogos participantes, destacam-se as relações realizadas entre o pensamento complexo contido no livro de referência para o curso - Saberes necessários para à educação do futuro de Morin - e a disciplina de formação e atuação.

No primeiro capítulo, Morin trata sobre o saber As cegueiras do conhecimento: o erro e a ilusão. O autor (2000, p. 19) destaca que "todo conhecimento comporta o risco do erro e da ilusão." Mesmo o conhecimento científico é passível de erros, ilusões e cegueiras, cabendo à educação a identificação da origem. Encontra-se na produção REA do Participante 1, a argumentação sobre esse capítulo:

P1: Sendo uma produção humana, os conhecimentos não representam verdades absolutas, visto que somos passiveis de erros e acertos. Talvez para determinada época, período ou contexto, podem até se traduzir como imutáveis e dar conta das necessidades daquela sociedade. No entanto, principalmente pelos avanços tecnológicos e científicos, podem sofrer reformulações, ser mudado ou até mesmo substituído por uma teoria mais completa de acordo com os moldes ou contextos da atualidade. Assim, não devemos cair no erro do conhecimento pronto e acabado, que nos levam a ilusões de verdades absolutas.

No segundo capítulo, o autor destaca o saber Os princípios do conhecimento pertinente. Para Morin (2000, p. 35), "para articular e organizar os conhecimentos e assim reconhecer e conhecer os problemas do mundo, é necessária a reforma do pensamento". Esse pensamento necessita levar em consideração o contexto, o global, o multidimensional e o complexo. Destaca-se a explanação sobre esse saber, realizada pelo Participante 3:

P3: O educador deve trabalhar de forma transversal e interdisciplinar, propor situações onde haja a interação e aprendizado do conteúdo formal da disciplina para ousar chegar ao seu objetivo, fazendo com que o educando 
tenha reconhecimento de si próprio e do outro, despertando seu o senso crítico de cidadania, de respeito, de valores, tornando-o mais confiante em superar os desafios, criando situações de aprendizado, com condições favoráveis ao desenvolvimento cognitivo do educando, orientando-o e dando-lhe autonomia, pois a interação acontece constantemente.

No terceiro capítulo, o saber que Morin descreve é Ensinar a condição humana. "Conhecer o humano é, antes de tudo, situá-lo no universo, e não separá-lo" (MORIN, 2000, p. 47). A visão de homem precisa ser ampliada de acordo com a tríade indivíduo, sociedade e espécie. Sempre num processo recursivo, retroativo, dialógico, dialético. Analisando o texto do Participante 4, destacamos:

P4: [...] deve se tratar desenvolvimento e a aprendizagem como um ser humano em constante interação no contexto histórico e social em que devem ser considerados aspectos físicos, afetivos, psicológicos, intelectual e social.

O quarto capítulo, Ensinar a identidade terrena, é um saber que situa a condição humana no mundo, na era planetária. De acordo com Morin (2000, p. 76), precisa-se "[...] aprender a ser, viver, dividir e comunicar como humanos do planeta Terra, não mais somente pertencer a uma cultura, mas também ser terrenos". Para tal, é preciso ensinar a ética da compreensão planetária. Sobre esse saber, o Participante 4 discorre que:

P4: A importância de conhecer o outro e as suas potencialidades, saber se relacionar, conhecer outras culturas, abordar questões voltadas a diversidade, á natureza e a espécie humana, sendo essenciais para o desenvolvimento humano.

No quinto capítulo, Enfrentar as incertezas, Morin argumenta que é preciso incluir o ensino das incertezas, as quais surgiram nas ciências ao longo do século XX. Ele argumenta que se precisa saber "[...] esperar o inesperado e trabalhar pelo improvável” (MORIN, 2000, p. 92). No trecho abaixo, do Participante 5, o saber em questão está destacado: 
P5: Esta temática despertou o interesse e curiosidade por saberes diversos, numa possibilidade de desenvolver conteúdos mais significativos e dentro do cotidiano dos alunos, que muitas vezes passam despercebidos. Interessante como pequenas mudanças no dia-a-dia de sala de aula, pode trazer diferentes contribuições e, consequentemente, mais vontade de aprender.

O sexto capítulo, Ensinar a compreensão, traz um saber que diferencia ensinar e compreender. Para Morin (2000, p. 93), "educar para compreender a matemática ou uma disciplina determinada é uma coisa; educar para a compreensão humana é outra". Não há como ensinar a compreensão humana sem que haja reforma "planetária das mentalidades". O Participante 1 realiza reflexões acerca desse saber, trazendo um exemplo pertinente:

P1: Educar para a concepção de dimensionamento global, significa que precisamos nos reconhecer como parte e integrantes de um mundo em constante desenvolvimento e mudanças, que não somos isolados do mundo, vinculados apenas no entorno próximo, mas que pertencemos a um plano muito maior, onde as ações individuais e ou coletivas atravessam fronteiras e pode interferir em aspectos ou no próximo em outro extremo do planeta. Nesta ótica, isto remete em, por exemplo, a fatos de como o derretimento das geleiras lá do Polo Norte, pode interferir no clima de todo o mundo ou no inverso, como ações aqui nas Américas podem contribuir para o derretimento das geleiras do Polo Norte.

No sétimo e último capítulo, Morin traz como saber A ética do gênero humano. Nesse saber, o autor (p. 105) retoma a tríade indivíduo, sociedade e espécie argumentando que são inseparáveis e coprodutores, sendo esta a base para ensinar a ética do futuro. O Participante 6 destaca como é possível trabalhar esse saber e quais contribuições apresentadas para a educação:

P6: Compreendo que não é fácil tratar da educação e torná-la um exemplo coletivo, mas com esforço e busca de aperfeiçoamento conseguimos realizar transformações e torná-la mais eficiente. Com análise e instrução desses saberes, podemos ter uma preparação que nos oportuniza ferramentas para nosso desenvolvimento e, assim podemos tornar a educação com mais 
qualidade e acessivel para todos. Pode-se notar que elaborar um plano de aula calcada nos sete saberes, subsidia um trabalho mais consciente e reflexivo, alavancando, assim, consequentemente a qualidade da educação, onde os alunos podem ter visão baseada na temática relacionada com os saberes necessários para aquisição do conhecimento.

Com as Produções Individuais (REA) dos participantes, pôde-se constatar que ocorreu articulação entre o que foi estudado durante o curso sobre os REA e os saberes necessários à Educação do futuro, que representam os pressupostos teóricos do pensamento complexo. No questionário inicial do curso, $50 \%$ dos inscritos relataram que tinham ouvido falar nas temáticas, porém não tinham conhecimento e $11 \%$ não tinham nenhum conhecimento. No final do curso, com as Produções Finais (REA), construídas pelos participantes, constatam-se resultados positivos e satisfatórios de acordo com os objetivos propostos.

\section{Considerações finais}

Este artigo teve como objetivo apresentar suscintamente os resultados da pesquisa colaborativa, desenvolvida por meio do curso: Saberes necessários à educação do futuro: recursos educacionais abertos à luz do pensamento complexo, o qual se constitui parte de investigação de doutorado em andamento. Os participantes do curso foram professores e pedagogos da Rede Estadual de Educação, do município de Campina Grande do Sul (PR). Foi possível concluir que o curso on-line proporcionou aos participantes o conhecimento sobre o conceito de REA: buscou-se auxiliar os professores na elaboração e produção de Recursos Educacionais Abertos, como material pedagógico a ser disponibilizado na internet. No entanto, esta elaboração e/ou produção não poderia se dar sem uma fundamentação teórica. De maneira que se utilizou da obra de Morin: Os sete saberes necessários à educação do futuro, que sistematiza os princípios cognitivos do pensamento complexo.

No início do curso, a maioria dos participantes relatou não conhecer ou conhecer pouco sobre as temáticas. Ao final, os resultados com a produção individual mostraram que ocorreu a construção do conhecimento 
teórico e prático sobre os REA e o pensamento complexo. O curso, além de ser uma prática metodológica por meio da interconexão dos saberes, proporcionou a reflexão teórica sobre a prática à luz do pensamento complexo com as atividades dos fóruns de discussão e com as produções individuais.

As discussões teóricas sobre os saberes necessários à educação do futuro, nos fóruns, apontaram que os participantes realizaram reflexões colaborativas importantes sobre suas práticas atuais e sobre a educação que Morin propõe: reforma de pensamento e religação dos saberes. Constatou-se que o curso possibilitou, não só o conhecimento teórico, mas também a produção de prática pedagógica de acordo com a formação disciplinar de cada participante colaborador da pesquisa. As diversas áreas do conhecimento puderam dialogar, possibilitando a interligação e ampliação do conhecimento de cada um.

Com a análise das oito produções finais (REA) dos participantes, conclui-se que o curso de formação continuada on-line desenvolvido aponta caminho possível de metodologia inovadora para a construção de novos saberes e, consequentemente, possibilidade de mudança da prática pedagógica de professores e pedagogos.

\section{Referências}

BIZARRIA, F. P. A. Resenha: Os sete saberes necessários à educação do futuro. Debates em Educação, Maceió, v. 7, n. 13, jan./jun. 2015. Disponível em: <http:// www.seer.ufal.br/index.php/debateseducacao/article/view/891/0>. Acesso em: 03 abr. 2018.

FERREIRA, M. S.; IBIAPINA. I. M. L. M. A pesquisa colaborativa como espaço formativo. In: MAGALHÃES, M. C. C.; FIDALGO. S. S. (Org). Questões de método e de linguagem na formação docente. São Paulo: Mercado das Letras, 2011. p.119-140.

MORIN, E. Os sete saberes necessário à educação do futuro. São Paulo: Cortez; Brasília: UNESCO, 2000. Disponível em: <https://bioetica.catedraunesco.unb. br/wp-content/uploads/2016/04/Edgar-Morin.-Sete-Saberes.pdf $>$. Acesso em: 03 abr. 2018. 
MORIN, E. Os sete saberes necessários à educação do futuro. São Paulo: Cortez: Brasília, UNESCO, 2011a.

MORIN, E. Introdução ao pensamento complexo. Porto Alegre: Sulina, 2011b.

OLIVEIRA, C. P. S. Resenha bibliográfica. Revista de Ensino de Geografia, Uberlândia, v. 7, n. 12, p. 148-150, jan./jun. 2016. Disponível em: <http://www. revistaensinogeografia.ig.ufu.br/N12/Resenha-1-Revista-Ensino-Geografia-v7n12-Oliveira.pdf>. Acesso em: 03 jul. 2018.

PEREIRA, Â. M. de A. Uso de Recursos Educacionais Abertos (REA) na educação superior/UAB: sonho ou realidade? 161f. Dissertação (Mestrado) — Universidade Federal de Pernambuco, Recife, 2015. Disponível em: <http://www.repositorio. ufpe.br/handle/123456789/13845>. Acesso em: 08 jul. de 2017.

PETRAGLIA, I. Edgar Morin: a educação e a complexidade do ser e do saber. Petrópolis: Vozes, 2011.

SÁ, R. A.; CARNEIRO, S. M. M.; LUZ, A. A. A escola e os sete saberes: reflexões para avanços inovadores no processo educativo. Revista da FAEEBA - Educação e Contemporaneidade, Salvador, v. 22, n. 39, p. 159-169, jan./jun. 2013. Disponível em: <www.revistas.uneb.br/index.php/faeeba/article/download/336/286>. Acesso em: 03 jul. 2018.

SANTOS, A. I. dos. Recursos Educacionais Abertos no Brasil: o estado da arte, desafios e perspectivas para o desenvolvimento e inovação. Trad. DB Comunicação. São Paulo: Comitê Gestor da Internet no Brasil, 2013. Disponível em: <http://cetic. br/publicacoes/2012/rea-andreia-inamorato.pdf>. Acesso em: 21 de mar. 2018.

Recebido: 29/07/2018

Received: 07/29/2018

Recibido: 29/07/2018

Aprovado: 11/02/2019

Approved: 02/11/2019

Aprobado: 11/02/2019 